\title{
POSITIONAL HYPOXAEMIA FOLLOWING POST-TRAUMATIC PULMONARY INSUFFICIENCY
}

\author{
Jonathan D. Katz and Paul G. Barash
}

IN RECENT YEARS attention has been focused upon the relationship of pulmonary function and body position. The postural variations in gas exchange have been demonstrated to be clinically significant in a variety of circumstances associated with respiratory dysfunction. ${ }^{1,2}$ The recognition of these variations in pulmonary function has also permitted their therapeutic application in the management of acute respiratory failure. ${ }^{3}$ The alterations in ventilation and perfusion as a consequence of position are in turn modified by numerous factors, possibly the most significant of which are the presence of lung disease, the use of mechanical ventilation, and the application of positive end expiratory pressure (PEEP).

Recently, we had the unique opportunity to observe the effects of changes in body position on ventilatory function in a patient with unilateral lung disease. Management of this patient provided insight into possible mechanisms involved in positional alterations in pulmonary function.

A 30-year-old female was involved in an automobile accident and had sustained a crushing injury to the entire right side of her body. Her injuries were extensive and required a right hemi-pelvectomy in the post-trauma period. In addition to multiple rib fractures, she had sustained a left haemo-pneumo-thorax with complete collapse of the entire left lung. Emergency treatment had been given at another hospital, and she had then been transferred to our hospital for intensive care. Mechanical ventilation through a tracheostomy was instituted with an Ohio 560 respirator. Chest $\mathrm{x}$-ray showed total opacity of the left chest with shift of the mediastinum to the left (Figure 1). Due to the initial extensive debridement required it was not possible to close the hemi-pelvectomy wound primarily and it was elected to permit closure by tertiary intent. The retro-peritoneal wound required extensive irrigation and frequent dressing changes in the right and left decubitus positions. Monitoring included a radial artery cannula and a Swan-Ganz pulmonary artery catheter.

After repeated fiberoptic bronchoscopy the left lung eventually re-expanded. Ultimately skin grafts were applied for wound closure. The patient's subsequent hospital course was essentially uneventful.

\section{METHODS}

The observations were made during positive pressure ventilation (PPV) with an $\mathrm{F}_{\mathrm{I}_{2}}$ of 0.5 and with zero end-expiratory pressure (ZEEP) or $5 \mathrm{~cm} \mathrm{H}_{2} \mathrm{O}(0.9$ $\mathrm{kPa}$ ) positive end expiratory pressure (PEEP). Ventilation was maintained with a tidal volume of $15 \mathrm{ml} / \mathrm{kg}(900 \mathrm{ml})$ and ten respirations per minute. Following a

Jonathan D. Katz, M.D., Assistant Professor of Anesthesiology.

Paul G. Barash, M.D., Assistant Professor of Anesthesiology, Director Surgical Intensive Care Unit, Yale University School of Medicine, Department of Anesthesiology, 333 Cedar Street, New Haven, Connecticut 06510. 


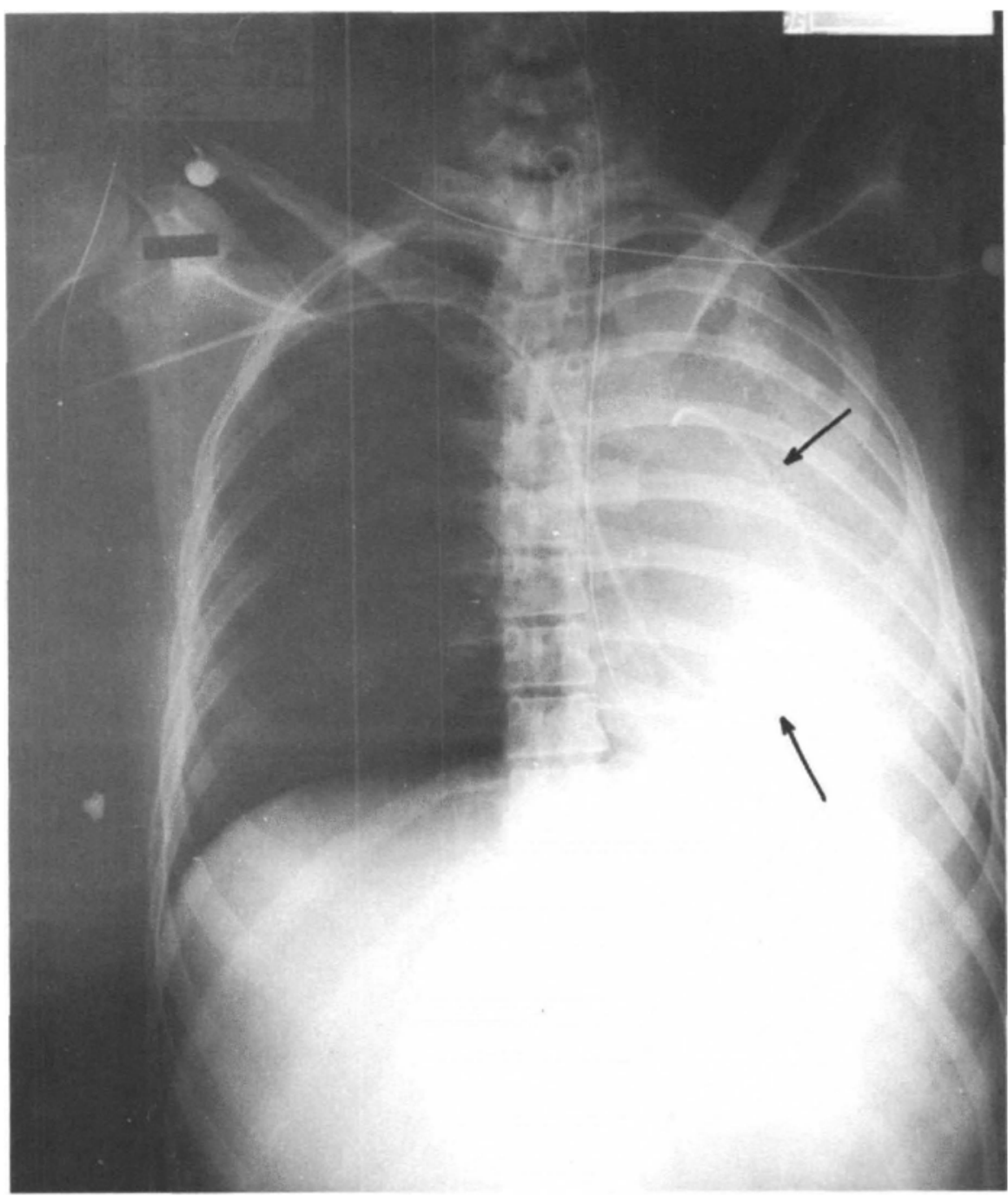

FrGure 1. Chest X-ray during study shows left hemithorax totally opacified. The extreme shift of mediastinal structures to the left can be appreciated by the position of the Swan-Ganz(1) pulmonary artery catheter (arrow).

30 minute control period, data were collected for each of the following positions: supine, right lateral decubitus, and left lateral decubitus. The patient was placed into the supine position between one lateral position and the other. Any necessary minor therapeutic maneuvers (including tracheal suctioning) were done within the first few minutes of observation. Major therapeutic interventions (such as blood transfusion and bronchoscopy) were carried out at least three hours before data collection. Data were obtained on each of three successive days, while the pathological lung changes remained relatively constant. Tidal volume and minute volume were measured with a Wright respirometer attached to the expiratory limb of the ventilator. Effective compliance is expressed as the ratio of tidal volume 
TABLE I. Data collected with mechanical ventilation and ZEEP.
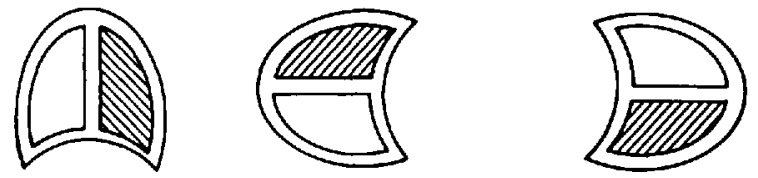

SUPINE

RIGHT LATERAL DECUBITUS

LEFT LATERAL DECUBITUS

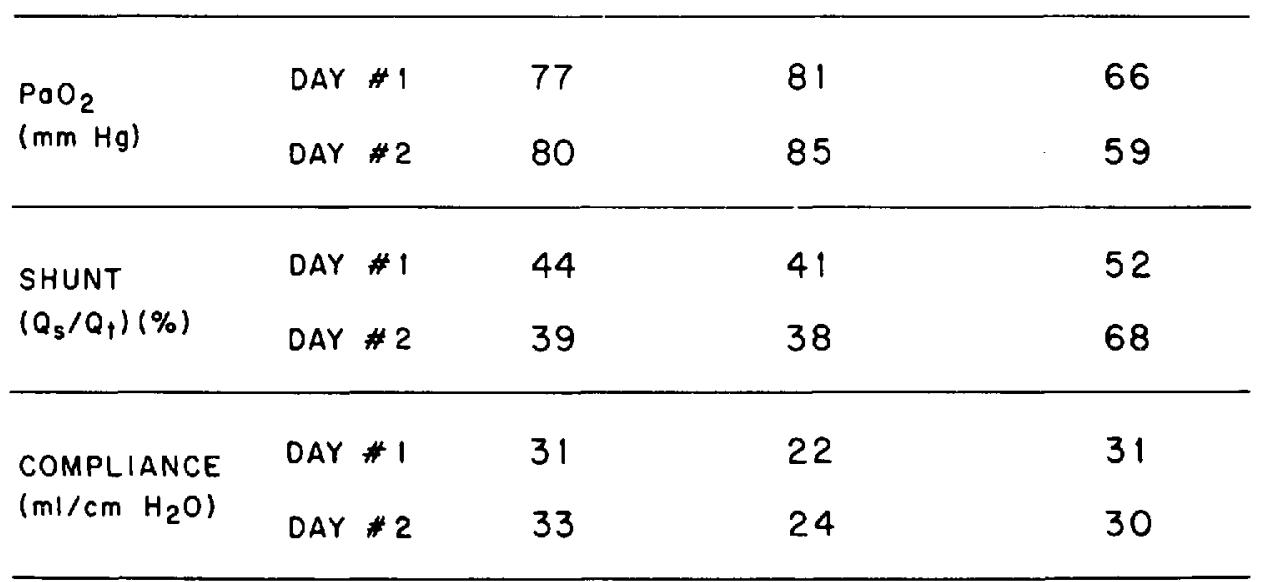

$\mathrm{PaO}_{2}$

SHUNT (QS/QT)

COMPLIANCE
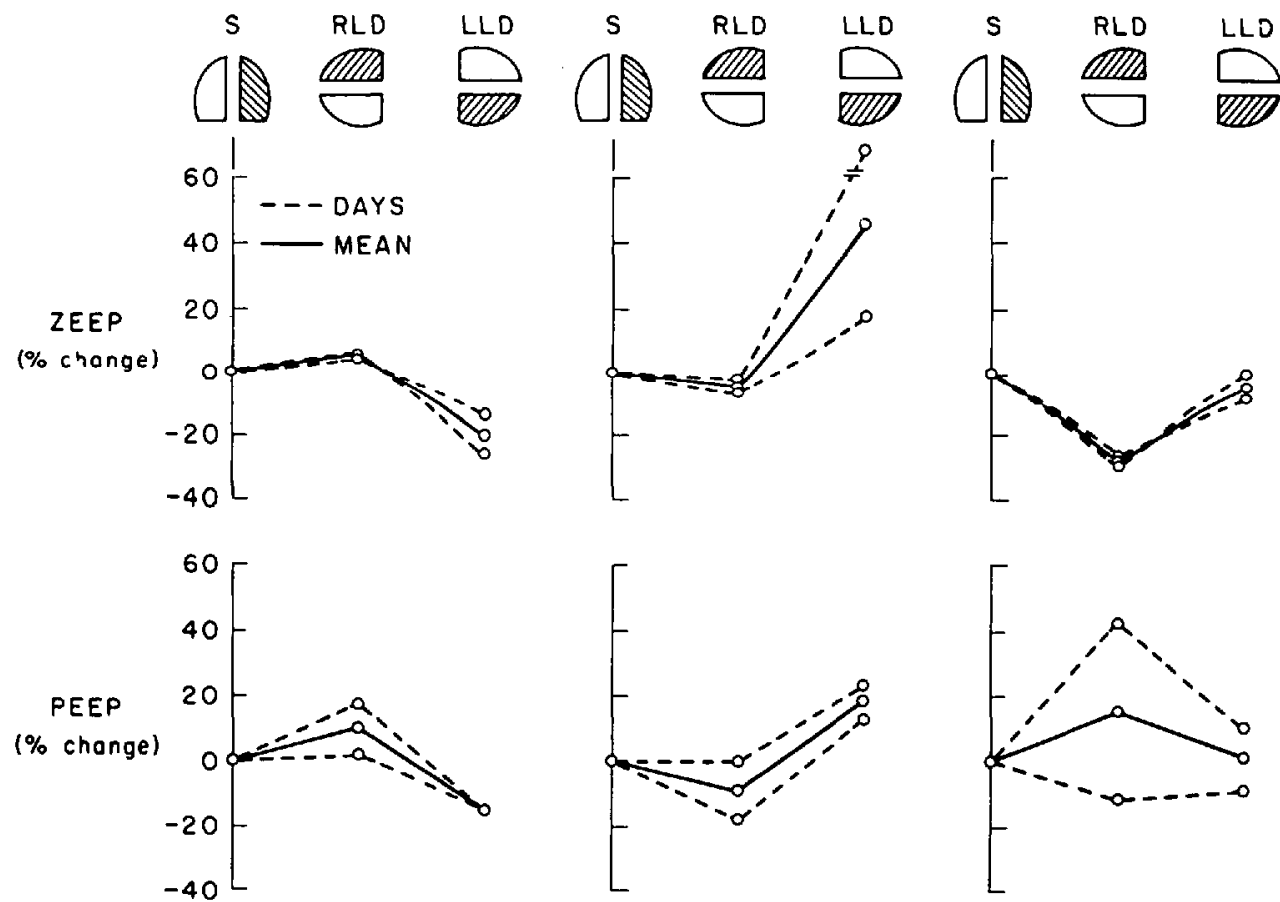

Figure 2. Data collected under conditions of ZEEP and PEEP. The results are expressed as per cent change of the control (supine) position. 
to net peak inspiratory pressure. Blood gas determinatoins were done on the Radiometer Acid Base Analyzer. Cardiac output was determined with the aid of an Edwards Laboratories 9510 thermodilution cardiac output computer.

\section{Results}

Table I and Figure 2 provide data collected from positional changes with positive pressure ventilation and ZEEP. Using the supine position as a control, movement to the right lateral decubitus, with the ("good") right lung dependent, produced a 5.5 per cent increase in $\mathrm{Pa}_{\mathrm{O}_{2}}$, a 4.5 per cent decrease in venous admixture $\left(\mathrm{Q}_{\mathrm{s}} / \mathrm{Q}_{\mathrm{t}}\right)$ and a 28 per cent decrease in dynamic compliance. This is in marked contrast to the situation when the (diseased) left lung was in the dependent position. In this posture the $\mathrm{Pa}_{\mathrm{O}_{2}}$ decreased by 20 per cent and the $\mathrm{Q}_{\mathrm{s}} / \mathrm{Q}_{\mathrm{t}}$ increased by 46 per cent. The compliance was decreased by 4.5 per cent. These positional changes did not significantly affect the cardiac output (mean $=5.1 \mathrm{l} / \mathrm{min}$ ) or pulmonary vascular resistance (less than three resistance units [normal 0-3 resistance units]).

Table II and Figure 2 summarize the results when PEEP ( $5 \mathrm{~cm} \mathrm{H}_{2} \mathrm{O} ; 0.9 \mathrm{kPa}$ ) was instituted. With the "good" lung dependent the $\mathrm{Pa}_{\mathrm{O}_{2}}$ increased by 10 per cent. The $Q_{*} / Q_{t}$ decreased by 8.5 per cent and dynamic compliance improved by 15 per cent. Application of PEEP with the diseased lung dependent produced a smaller relative decrease in $\mathrm{Pa}_{\mathrm{O}_{2}}$ ( 15 per cent) as compared with that seen with ZEEP. The $Q_{s} / Q_{t}$ was increased (18.5 per cent) and compliance showed no change. The application of PEEP produced a fall in cardiac output of 14 per cent in the right and 6 per cent in the left lateral position. Pulmonary vascular resistance remained

TABLE II. Data collected with mechanical ventilation and PEEP.
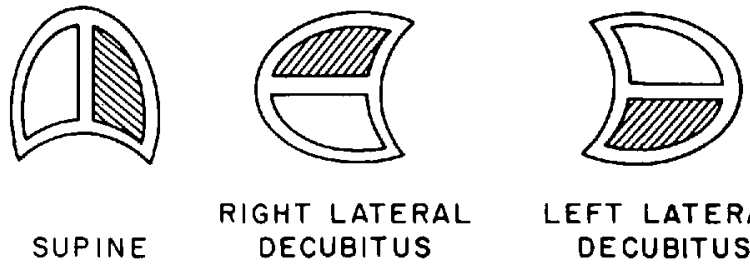

RIGHT LATERAL DECUBITUS

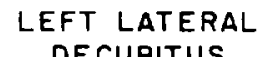
DECUBITUS

\begin{tabular}{lcccc}
\hline $\begin{array}{l}\mathrm{PoO}_{2} \\
(\mathrm{~mm} \mathrm{Hg})\end{array}$ & DAY \#1 & 73 & 86 & 62 \\
\hline DAY \#3 & 116 & 118 & 99 \\
$\begin{array}{l}\mathrm{SHUNT} \\
\left(\mathrm{Q}_{\mathbf{3}} / \mathrm{Q}_{1}\right)(\%)\end{array}$ & DAY \#1 & 46 & 38 & 52 \\
\hline & DAY \#3 & 21 & 21 & 26 \\
$\mathrm{COMPLIANCE}$ & DAY \#1 & 34 & 30 & 31 \\
$\left(\mathrm{mI} / \mathrm{CM} \mathrm{H}_{2} \mathrm{O}\right)$ & DAY \#3 & 31 & 44 & 34 \\
\hline
\end{tabular}


within normal limits and there were no consistent changes in relation to body position.

\section{Discussion}

The effects of posture on ventilation include changes in the intra-pulmonary distribution of gases, compliance, and pulmonary blood flow. During spontaneous respiration in the upright position, the base of the lung receives approximately twice the ventilation of the apex. ${ }^{4}$ These regional differences in ventilation are due to the existence of a vertical intra-pleural pressure gradient imposed by the forces of gravity. Alveoli at the base of the lung are situated on a high compliance segment of the pressure volume curve and thus expand maximally on inspiration. In contrast, the apical alveoli sit on a flat portion of the compliance curve and receive proportionally a smaller volume upon inspiration. Likewise, in the supine position, ventilation to the posterior portion of the lung exceeds that to the anterior.

In the lateral position with spontaneous ventilation, the lower lung receives a greater proportion of ventilation. ${ }^{5}$ This occurs for two reasons. In the lateral position the dependent hemidiaphragm is pushed high into the thorax by the abdominal viscera. In this position it has a greater mechanical advantage and is able to contract more effectively. The greater compression by the abdominal viscera on the dependent lung also causes it to rest (at functional residual capacity) close to the residual volume, while the upper lung is closer to its inspiratory capacity." This places the lower lung at a more favorable position on its compliance curve and thus permits greater expansion.

When positive pressure ventilation is instituted these relationships are altered. During positive pressure ventilation in the lateral position the contribution of the diaphragm is diminished. With the exception of the effects of local airway resistance, this results in a spacial distribution of gases solely determined by regional differences in compliance. Rheder has shown that the compliance of the dependent hemithorax is less than that of the nondependent one. ${ }^{7}$ Therefore, as one might expect, the dependent lung receives a smaller proportion of the total ventilation during positive pressure ventilation.

In the aforementioned case, the changes in compliance and $\mathrm{Pa}_{\mathrm{O}_{2}}$ under conditions of ZEEP further demonstrate the effects of posture on regional ventilation. With the "diseased" lung dependent, the $\mathrm{Pa}_{\mathrm{O}_{2}}$ decreased and the compliance was essentially unchanged when compared to the supine position. When the "good" lung was dependent, the $\mathrm{Pa}_{\mathrm{O}_{2}}$ increased and the compliance decreased. These findings are consistent with the hypothesis that positive pressure ventilation is preferential to the upper lung. When the upper lung is diseased, gas is redirected to the lower lung at the expense of a significant decrease in compliance and elevation in the inspiratory pressure. The greater gas flow to the lower lung is better matched by the increased blood flow also to the dependent lung and an improved $\mathrm{Pa}_{\mathrm{O}_{2}}$ results. When the nondependent lung is "good", there is no added impediment to gas flow to this lung and therefore dynamic compliance is only slightly diminished. However, a ventilation perfusion mismatch is created with greater blood flow but less ventilation to the dependent lung and thus a decrease in $\mathrm{Pa}_{\mathrm{O}_{2}}$ is observed. 
The situation with PEEP is somewhat different. Rheder has shown that application of PEEP increases FRC in the dependent lung. ${ }^{8}$ This serves to preferentially improve compliance and ventilation of the lower lung. Our observations substantiate this fact. In this patient, with the "good" lung dependent, under conditions of PEEP compliance was improved when compared to a similar situation with ZEEP (Figure 2). It should be noted that five hours before the beginning of measurements on day three, fiberoptic bronchoscopy had been performed, which may have influenced this set of compliance measurements. However, at the time of our study, no changes in the "control" $\mathrm{Pa}_{\mathrm{O}_{2}}$ or the chest X-ray were observed. With the diseased lung dependent (PEEP), there are no significant changes in compliance when compared to ZEEP. This may be due to the fact that significant loss of lung volume results in a reduced FRC which could not be offset by the low level of PEEP used ( $5 \mathrm{~cm} \mathrm{H}_{2} \mathrm{O}$ or $0.9 \mathrm{kPa}$ ). Perhaps, if a higher level of PEEP were used, an improvement in compliance with the diseased lung dependent would also be noted.

In contrast to the situation with ventilation, blood flow through the pulmonary vascular bed is almost entirely determined by the forces of gravity. Kaneko has demonstrated that perfusion is gravity-dependent and related to the relative magnitudes of the regional pulmonary vascular and alveolar pressures. ${ }^{8}$ Although local factors such as hypoxaemia and acidosis can affect the distribution of blood flow, these are considered a weak stimulus for compensation. Arboreluis has demonstrated that in the lateral position, hypoxaemia cannot overcome the effect of gravity on pulmonary blood flow."

The aetiology of the positional hypoxaemia therefore appears to be a ventilationperfusion mismatch. Thus, under conditions of ZEEP, when the lung with unilateral disease is dependent, there is perfusion to non-ventilated alveoli resulting in hypoxaemia. With the diseased lung in the nondependent position there is an improved match of ventilation and perfusion. With the addition of PEEP and its effect on FRC, there is a general and consistent elevation in $\mathrm{Pa}_{\mathrm{O}_{2}}$. The improved oxygenation was apparent in both positions as compared to the situation with ZEEP, but a decrease in $\mathrm{Pa}_{\mathrm{O}_{2}}$ was still apparent with the "diseased" lung dependent as compared to the supine (control) position.

The clinical implications of these findings are important for the management of patients with post-traumatic pulmonary insufficiency. Changes in position may cause considerable alterations in pulmonary gas exchange. These ventilatory changes can be modified by PEEP. Positional hypoxaemia may result when significant unilateral lung disease is present.

\section{SUMMARY}

The effect of body position on ventilatory function was evaluated in a patient with unilateral lung disease. The patient's pulmonary dynamics were examined in the supine, right, and left decubitus positions under conditions of positive pressure ventilation with zero end-expiratory pressure (ZEEP) and $5 \mathrm{~cm}$ $\mathrm{H}_{2} \mathrm{O}(0.9 \mathrm{kPa})$ positive end expiratory pressure (PEEP).

When the patient was positioned so that the "diseased" lung was dependent, 
there was a marked decrease in $\mathrm{Pa}_{2}$ and increase in venous admixture when compared to the values in the supine position. These changes were relatively greater in the ZEEP, than the PEEP situation. When the "diseased" lung was not dependent, there was an increase in $\mathrm{Pa}_{\mathrm{O}_{2}}$ and a decrease in venous admixture. This was most pronounced when PEEP was applied.

Changes in body position may result in clinically significant alterations in pulmonary gas exchange, especially in patients with pre-existing pulmonary dysfunction.

\section{RÉSUMÉ}

Nous avons pu étudier les effets de la posture sur la fonction respiratoire chez un malade présentant une atteinte pulmonaire unilatérale (pneumothorax avec collapsus complet d'un poumon). La dynamique pulmonaire de ce malade a été étudiée en décubitus dorsal, en décubitus latéral gauche et latéral droit, et ceci en respiration contrôlée avec pression de zéro en fin d'expiration (ZEEP) ou une pression positive de $5 \mathrm{~cm}$ fin d'expiration (PEEP).

En clécubitus latéral, lorsque le poumon malade était en position inférieure, on observait une diminution marquée de $\mathrm{Pa}_{0.2}$ et une élévation du shunt par rapport au décubitus dorsal. Ces changements étaient plus grands lorsque l'on n'utilisait pas la PEEP. Par contre, lorsque le poumon malade était en position supérieure, on constatait une élévation de la $\mathrm{Pa}_{\mathrm{O}_{2}}$ et une diminution du shunt, modifications qui étaient plus prononcées si l'on utilisait la PEEP.

Les changements de position peuvent influencer de façon significative les échanges gazeux pulmonaires, surtout en présence de pathologie pulmonaire.

\section{REFERENCES}

1. VaughN, R.W. \& Wise, L. Post-operative arterial blood gas measurement in obese patients: effect of position on gas exchange. Ann. Surg. 182: 705-709 (1975).

2. ZACK, M.B., Pontoppidax, H., \& Kazexi, H. Effect of lateral positions on gas exchange in pulmonary disease: a prospective evaluation. Am. Rev. Resp. Dis. 110: 49-55 (1974).

3. PIEHL, M.A. \& BRown, R.S. Use of extreme position changes in acute respiratory failure. Crit. Care Med. 4: 13-14 (1976).

4. WEST, J.B. Ventilation/blood flow and gas exchange. London, Blackwell Scientific Publications. 55-63 (1970).

5. Lillixcton, G.A., Fowler, W.S., Miller, R.D., \& Helisholz, H.F. Nitrogen clearance rates of right and left lungs in different positions. J. Clin. Invest. 38: 2026-2034 (1959).

6. Nuns, J.F. Applied respiratory physiology. New York, Appleton-Century Crofts. 132-138 (1969).

7. Rheder, K., Hatch, D.J., Sessler, A.D., \& Fowler, W.S. The function of each lung of anesthetized and paralyzed man during mechanical ventilation. Anesthesiology 37:16-26 (1972).

8. Rhedeh, K., Wenthe, F.M., \& Sessler, A.D. Function of each lung during mechanical ventilation with ZEEP and with PEEP in man anesthetized with thiopental-meperidine, Anesthesiology 39: 597-606 (1973).

9. Kaneko, K., Milic-Emill, J., Dolovich, M.B., Dawson, A., \& Bates, D.V. Regional distribution of ventilation and perfusion as a function of body position. J. Appl. Physiol. 21: 767-777 (1966).

10. Arhorelius, M., Lundin, G., Svanbehg, L., \& Defares, J.G. Influence of unilateral hypoxia on blood flow through the lungs in man in the lateral position. J. Appl. Physiol. 15: 595-597 (1960). 